\title{
An Analysis of Conjunctions as Cohesive Devices in High School Students' English Writing
}

\author{
Li Yingle and Zhao Xueai
}

\begin{abstract}
Cohesion and coherence have long been considered as important features of a good essay. Therefore, in many writing tests (e.g, IELTS, TOEFL, CET4, CET6), cohesion and coherence of articles are usually given a larger proportion of grade. This emphasis on cohesion and coherence has prompted English teachers to place special emphasis on the use of cohesive devices in English writing.

Studies of cohesion and coherence have been conducted all over the world since the publication of Halliday and Hasan's Cohesion in English in 1976. In particular, the use of cohesive devices in English writing has been a significant topic. However, the impact of the use of these devices on writings' quality is unclear.

Therefore, this paper aims to explore whether high school students use cohesive devices in English writing appropriately, with a particular focus on the issue of conjunction use. According to a considerable number of studies, the number of cohesive devices and the quality of writing barely have utilitarian purposes. The results of the present study show that the frequency of conjunctions has little to do with the quality of English writing. In addition, it is not the frequency of cohesive items that makes a text structured, but rather the appropriate use of conjunctive markers.
\end{abstract}

Index Terms-Cohesive devices, conjunction, English writing.

\section{INTRODUCTION}

The purpose of this research is to explore whether high school students use cohesive devices in English writing appropriately, and particularly conjunctions. This study is based on the cohesion theory of Halliday and Hasan [1], and will examine the use of several forms of conjunctions in the writing of high school students in English as a Second Language. Firstly, this chapter presents the research background of this study. Then, it points out the significance of this study

\section{A. Background of the Study}

Over the past few decades, interest in English discourse writing has grown dramatically. In particular, widespread studies have been conducted on cohesion and coherence, initiated by the publication of Halliday and Hasan's Cohesion in English in 1976. Cohesion and coherence have long been considered as important features of a good essay. Therefore, in many writing tests (e.g, IELTS, TOEFL, CET4, CET6), cohesion and coherence of articles are usually given a larger proportion of grade. For example, in the IELTS writing test,

Manuscript received August 9, 2019; revised September 16, 2019. This work is supported by the Northwestern Polytechnical University, China.

Li Yingle and Zhao Xueai are with the School of Foreign Languages of Northwestern Polytechnical University, China (e-mail: yingle_li@163.com, xazhao@nwpu.edu.cn). the examiner scores from the following four aspects: Task1 / Task2, coherence and cohesion, vocabulary and sentence richness, grammatical accuracy.

This emphasis on coherence and cohesion has prompted English teachers to place special emphasis on the use of cohesive devices in English writing teaching, and has led researchers to this field. The most common means of cohesion is the use of conjunctions (such as and, but, so) or adverbial conjuncts (such as moreover, however, therefore, etc.) to indicate the logical and semantic relationship in discourse.

\section{B. Significance of the Study}

As mentioned above, the most common means of cohesion is the use of conjunctions or adverbial conjuncts to indicate the logical and semantic relationship in discourse. However, the impact of the implication of these devices on writing's quality is unclear.

A number of studies have examined adult second language (L2) writing and have confirmed that there exist positive correlations between the presence of local cohesive devices and writing quality [2]. Moreover, recent computational studies have reported differences between local and global cohesive devices and their relation to the writing quality of L1 writers, with local cohesion negatively related to writing quality and global cohesion positively related to writing quality [3].

Therefore, understanding the differences between these types of cohesive devices in L2 writing may help explain their relationship with L2 writing proficiency. Furthermore, this study can provide pedagogical implications for English teaching and learning.

\section{LITERATURE REVIEW}

In this chapter, previous research on cohesive devices are reviewed and divided into sub-sections based on the genres (discourse types) to which the analyzed texts belong. Firstly, in this section, research on university and school students' pieces of writing (academic writing). Secondly, studies on the use of cohesive devices in non-academic discourse types are reviewed.

\section{A. Studies of Cohesive Devices in Academic Writing}

A considerable number of studies on cohesive devices in academic writing have focused on the potential relationship between the use of cohesive devices in students' writings and the quality of writing. there is no certain answer to whether or not the use of cohesive devices leads to high-quality texts. This section reviews previous research on the role and the impact of cohesive devices on academic discourse.

Yang and Sun use a random sample of 30 sophomore 
university students and 30 fourth year, university students [2]. The results seem reliable as they use t-tests, which indicate that the observed difference between the two sample groups is statistically significant and is not due to chance. This study thus confirms there is a significant link between cohesive devices and the quality of argumentative writing.

Furthermore, Mohamed and Mudawi have found that using cohesive devices in writing leads to high writing quality [4]. However, this paper fails in the validity and reliability of quantitative designs. That is, the questionnaire used in this study has been distributed to a number of teachers who work in different universities while it was conducted on 100 students from a single university in Sudan. this would challenge the claims that the teachers' responses can be taken as a basis for the study being conducted on a group from one university.

The following sub-section reviews the literature on cohesive devices in non-academic text types.

\section{B. Studies of Cohesive Devices in Non-academic Writing}

Jabeen, Mehmood and Iqbal explore how cohesive devices [5], particularly reference, substitution and ellipsis, contribute to meaning in Chekhov's The Bear (non-academic writing). The paper mentions some major concepts in textual analysis, such as cohesion, coherence and stylistics. This paper also contains a summary of analysis instrument -- the three cohesive devices, but has its major drawback that does not provides enough examples on them. The study merely explains the selected texts from the play, identifies instances of cohesive devices, and yet fails to achieve its goal to create a relationship between the meaning of the text and the use of the cohesive devices. For example, the paper claims that the instances of clausal substitution used in the play indicate a lack of respect, but have not provided any social or textual background information to support this claim, which makes it quite subjective.

Kaur analyses Keats's "Ode to Autumn" in terms of cohesive devices, employing Halliday and Hasan's model [6] The study aims to analyze how cohesive devices connect together the various parts of the text. However, the absence of a literature review section makes it hard to recognize the contribution of this paper. In essence, almost all the research has not leaven the surface level and can be regarded as attempts to list the cohesive devices used in the selected literary texts.

Abu Ayyash analyses the newspaper article from the perspective of cohesive devices, but it goes beyond text functions to connect context and genre [7]. This study is based on illustrative statistics, which can play a role in linking with any means of connection.

Bae explores the relationship between writing quality and cohesion by studying children's narrative essays [8]. In addition to quantitative tools such as percentages, correlation and multiple returns, the results of this study have also been verified through periodic analysis. The results of Bae are relatively high compared to others findings. Although the research results related to connective tools and writing are consistent, they insist that not all types of connectors are involved. But Green challenged the results of the study and found no indication of various proficiency levels [9].

\section{THEORETICAL FRAMEWORK}

An important distinction in cohesion study is the difference between cohesion and coherence. In this chapter, the definitions of and the differences between cohesion and coherence will first be illustrated; secondly, the categories of cohesive devices will be introduced, which is also the model used for this research.

\section{A. Cohesion and Coherence}

Cohesion generally refers to the presence or absence of linguistic cues in the text that allow the reader to make connections between the ideas in the text [1]. Generally, these cues are local in nature, but they can also be based on global or text cohesion. Examples of local cohesion cues include overlapping words and concepts between sentences and explicit connectives such as because, therefore, and consequently [1]. Examples of global cohesion cues include semantic and lexical overlap between paragraphs in a text so that words or ideas in one paragraph are repeated in subsequent paragraphs. In addition, cohesion can be measured at the text level. One example of this is givenness in which cohesion is measured across the text based on the number of words that are new or given. In general, global and textual cohesion cues are more implicit than local cohesion cues.

In contrast to cohesion, coherence refers to the understanding that the reader derives from the text, in other words, the coherence of the text in the mind of the reader. Coherence depends on a number of factors including cohesion cues and non-linguistic factors such as prior knowledge and reading skill [3].

A number of studies have shown that cohesive devices are important indicators of text comprehensibility. For instance, an increase in text cohesion generally leads to greater comprehension of a text [3]. However, the facilitate effects for cohesive device are stronger for low-knowledge readers than high-knowledge readers [3]. In conclusion, these studies have indicated that local and textual cohesion are either not related or negatively related to human ratings of text coherence.

\section{B. Cohesive Devices}

Cohesive devices can be divided into five categories, which are: reference, substitution, ellipsis, conjunction and lexical cohesion [1]. In this chapter, these five categories are divided into four parts, which are references (1), substitution and ellipsis (2), conjunctions (3) and lexical cohesion (4), and will be briefly introduced.

\section{1) References}

References are used to refer to something else for their interpretation. They occur when the reader has to retrieve the identity of what is being mentioned from either within or outside the text. They are categorized in three types: personal, demonstratives and comparatives. Each category will be explained briefly and followed by examples. Halliday and Hassan divided references into two patterns: situational and textual references [1]. The former is labeled exophoric, which "looks outside the text to the situation in which the text occurs for the identity of the item being referred to" (p. 116). On the contrary, textual references, known as endophora, refer to something within the text. They are classified into 
anaphoric references (preceding the text) and cataphoric references (following the text) [1]. For example, the book talked about punctuation. It was published in 1990. It refers to the book which is an item mentioned earlier within the text.

\section{2) Substitution and ellipsis}

Substitution happens when a word/phrase is substituted for another. Substitution can be nominal (same, one, and ones), verbal (do), and clausal (not, so). An example of nominal substitution is: which cupcake do you like? I'd like the chocolate one, please. One replaces the noun cupcake.

Ellipsis corresponds to the omission of elements with the assumption that they will be understood by the reader or listener. They can be recovered by referring to a preceding item in the text. Ellipsis is generally an anaphoric relation but can occasionally be exophoric [1]. Similar to substitution, the omitted item can be a noun, a verb or a clause.

\section{3) Conjunction}

Conjunctions show the relation between clauses and connect their ideas together. Conjunctions contribute to the semantic organization of text thus standing on their own as a category covering the usage of adjunct-like elements in the sentences. Furthermore, they express the logical meanings of elaboration, extension and enhancement. Bloor. $\mathrm{M}$ and Bloor. $\mathrm{T}$ grouped them into four classes: additive, adversative, causal and temporal [10]. For example: I was preparing for the party since morning and cooking a lot of food (Additive). However, I was not exhausted (Adversative). So by the end of the day, everything was ready (Causal). Then, guests started to arrive (Temporal).

\section{4) Lexical cohesion}

Lexical cohesion can be defined as "achieving cohesive effect through vocabulary selection" [1]. Lexical cohesion is the most important form of cohesive ties. The main kinds of lexical cohesion are repetition, synonymy, antonymy, hyponymy, meronomy and collocation.

\section{RESEARCH METHODOLOGY}

In this chapter, the framework for data analysis will be described in detail. In brief, this research adopts a set of procedures for the analysis of conjunctions proposed by Halliday and Mathiessen [11]. Then, details about the data collection will be given.

\section{A. Framework for Data Analysis}

Since the analysis in this paper is limited to the use of conjunctive cohesive devices, more detailed descriptions of conjunctions will be given here.

Conjunctions are the source of transformation of internal elements in discourse development. Halliday and Hassan have divided conjunctions into four categories according to the different semantic relations expressed by the connection: Additive, Causal, Adversative and Temporal [1]. In some conjunctive relationships, we can feel the existence of semantic relations because of the existence of other conjunctive elements, but they are not shown in sentences. This type is called an implicit conjunction. However, we should not assume that conjunctions exist where they are not expressed. Whether explicit conjunctions exist or not is one of the main variables in English texts, whether between registers or between texts in the same register. Therefore, in order to avoid ambiguity and confusion, conjunctions need to be expressed. On this basis, Halliday puts forward some other nouns which can provide good help for analysis: opposition, classification, additive, adversative, verificative, temporal, comparative, causal, conditional and conceptual [11]. In the following table, different connection relationships and their meanings are simply classified (see Table I).

\begin{tabular}{|c|c|c|c|}
\hline \multicolumn{2}{|c|}{ TABLE I: THE TYPES OF CONJUNCTIONS } \\
\hline Primary types & $\begin{array}{c}\text { Immediate } \\
\text { sub-types }\end{array}$ & Examples & Meaning \\
\hline \multirow{4}{*}{ Elaboration } & Appositive & $\begin{array}{c}\text { Thus, for example, } \\
\text { in other words }\end{array}$ & $\begin{array}{c}\text { Some element is } \\
\text { represented or } \\
\text { restated. }\end{array}$ \\
\cline { 2 - 5 } & Clarification & $\begin{array}{c}\text { Rather, at least, } \\
\text { by the way, } \\
\text { in short }\end{array}$ & $\begin{array}{c}\text { Summarises, } \\
\text { makes more } \\
\text { precise. }\end{array}$ \\
\hline \multirow{4}{*}{ Enhancement } & Temporal & $\begin{array}{c}\text { Then, next, } \\
\text { finally, in the end }\end{array}$ & $\begin{array}{c}\text { Related to time, a } \\
\text { short time } \\
\text { duration. }\end{array}$ \\
\cline { 2 - 5 } & Comparative & Likewise & Related to. \\
\cline { 2 - 5 } & Causal & $\begin{array}{c}\text { Hence, because of, } \\
\text { consequently, } \\
\text { on account of }\end{array}$ & $\begin{array}{c}\text { Relating to or } \\
\text { being a cause of } \\
\text { something. }\end{array}$ \\
\cline { 2 - 5 } & Conditional & $\begin{array}{c}\text { In that case, if not, } \\
\text { however }\end{array}$ & $\begin{array}{c}\text { One depends on } \\
\text { another. }\end{array}$ \\
\cline { 2 - 5 } & concessive & Even so, yet & Conceding. \\
\cline { 2 - 5 } & Variation & Alternatively & Related. \\
\cline { 2 - 5 } & Additive & Also, and, but & Inclusion. \\
\hline Extension & \multicolumn{2}{|c|}{} & \\
\hline
\end{tabular}

\section{B. Data Collection}

This study selects senior two students of high school in Shaanxi Province as research objects. To complete this analysis, a topic of "hard work and happiness" is given to students to write propositions, and strict rules of the number of words and the time for writing is set. In this study, stratified sampling and random sampling were used. The stratified sampling is carried out according to the actual proportion of gender (5.6/4.4) and arts and science (2/13). Random sampling is used to test 20 samples randomly from these samples.

After the completion of the composition, 80 English compositions are selected from the students by stratified sampling. The compositions of the students are scored by two school teachers. According to the College Entrance Examination English Composition Criteria, the compositions with less than 10 scores were the compositions that do not complete the tasks set by the test questions. They do not convey the information to the readers accurately, and the contents are too small, the vocabulary is limited, and they are considered of no research value. In this study, students' compositions with scores below 10 are excluded and the rest are divided into high-rated group and low-rated group. Then, 10 of them are randomly selected from high-rated group and low-rated group, totally 20 of them are input into documents, and a small corpus is established for analysis.

This paper uses terminologies from Halliday and Mathiessen for analysis. Halliday and Mathiessen have proposed and instantiated a set of procedures for the analysis of conjunction [11]. In addition, Halliday points out a way to the analysis which contains the following as samples: ap= appositive, ad $=$ additive , caus $=$ causal, cond $=$ conditional, conc $=$ concessive, temp $=$ temporal and $\Theta=$ implicit conjunction [11]. For instance, the following is an example extracted from Halliday's work ( p. 334): 
"Heat is only the motion of the atoms I told you about."

"Then (Cond) what is cold?"

"Cold is only absence of heat."

"Then (Cond) if anything is cold it means that its atoms are not moving?

"But (Comp) the atoms of a piece of ice are moving. They are moving quite fast, as a matter of fact (ap). But they are not moving as fast as the atoms of warm water."

The findings are placed in brackets, depicting the various forms of conjunctions employed by the writers.

After manual annotation of these 20 samples in documents by author, the manual annotation is double checked by two teachers to ensure the accuracy of annotation. Then the frequency of each type conjunctions and each group is calculated by using find function in document.

The T-test of SPSS19.0 is used to test the correlation between the frequency of conjunction use and the writing quality.

\section{Data Analysis}

Twenty texts have been analyzed, and as space is limited, this paper will not show all the details but represents the final result of this analysis.

TABLE II: THE OVERALL FREQUENCY OF CONJUNCTION USE

\begin{tabular}{|c|c|c|}
\hline $\begin{array}{c}\text { Total Number of } \\
\text { Conjunctions }\end{array}$ & $\begin{array}{c}\text { Total Number of } \\
\text { Propositions }\end{array}$ & $\begin{array}{c}\text { Average Number of } \\
\text { Conjunctions }\end{array}$ \\
\hline 120 & 20 & 6 \\
\hline
\end{tabular}

From the general situation of conjunction usage frequency, senior two students have a certain awareness of conjunction usage, and a certain number of conjunctions are used in each composition. As shown in Table II, the total use of conjunctions is 120 , and the average use of conjunctions per composition is 6 . The data shows that senior high school students have a strong sense of using conjunctions. They will use a certain number of conjunctions to concisely demonstrate and explain their views, and promote discourse development through the use of conjunctions. The reason may be that after learning English in junior high school and senior high school, students have mastered certain conjunctions and can consciously apply them to composition writing. It also proves that teachers emphasize the role of conjunctions in discourse construction in the process of teaching. In junior high school and senior high school, students are required to pay close attention to the coherence and cohesion of sentences and paragraphs.

TABLE III: THE OVERALL FREQUENCY OF THE USE OF DIFFERENT TYPES OF CONJUNCTIONS

\begin{tabular}{|c|c|c|c|}
\hline Composition & Elaboration & Extension & Enhancement \\
\hline Total & 4 & 79 & 37 \\
\hline Percentage & $3 \%$ & $66 \%$ & $31 \%$ \\
\hline
\end{tabular}

In the analysis of conjunction usage in compositions (see Table III), we can see that students use Extension conjunctions more frequently, accounting for $66 \%$ of the total number of conjunctions used in the selected text. At the same time, although the frequency is relatively high, there are many mistakes can be found in the use of conjunctions. The second most frequently used category is the Enhancement category, accounting for $31 \%$ of the total conjunction usage and making fewer mistakes. The least used by students is the
Elaboration category, which accounts for only $3 \%$ of the total number of conjunctions used. This shows that students have not yet mastered the conjunction connection mechanism. As Halliday said, the author should elaborate and defend his views in the text.

TABLE IV: THE OVERALL FREQUENCY OF THE USE OF CONJUNCTIONS OF DIFFERENT GROUPS

\begin{tabular}{|c|c|c|c|}
\hline Group & $\begin{array}{c}\text { Number of } \\
\text { compositions }\end{array}$ & $\begin{array}{c}\text { Number of } \\
\text { conjunctions }\end{array}$ & $\begin{array}{c}\text { Average } \\
\text { Number of } \\
\text { Conjunctions }\end{array}$ \\
\hline High-rated & 10 & 63 & 6.3 \\
\hline Low-rated & 10 & 57 & 5.7 \\
\hline
\end{tabular}

As Table IV shows, this study finds that the frequency of conjunctions used in high-rated group writing is higher than that in low-rated group writing, that is to say, the frequency of conjunctions used by high-level learners is higher than that of low-level learners. And from the average number of conjunctions in each composition, the number of conjunctions used in the high-rated group is also higher than that in the low-rated group. From this point, we can see that although both of the high-rated and low-rated groups have certain awareness of conjunction use, the high-rated group have stronger awareness of conjunction use.

In order to further verify this hypothesis, the T-test in SPSS19.0 is used to test the frequency of the use of conjunctions in different groups, and the results shows that the significant value is above 0.05 , the difference was not statistically significant. It can be concluded that although there are differences in the frequency of conjunction use between high-rated group and low-rated group, the difference is not significant. That is to say, the frequency of conjunctions has little to do with the quality of compositions.

\section{CONCLUSION}

\section{A. Major Findings of the Study}

The students use higher rates of extensive elements with 79 out of 120 conjunctions $(66 \%$ of the total number of conjunctions in the texts). However, in spite of their number of occurrences, there are numerous instances of wrong usages. Due to the purpose of this study is to find out the limited space, there will not listed these mistakes. Among all these mistakes, the misuse of 'and' is obvious, this confirms the earlier findings that there is a significant difference in the use of 'and between the high and the low-rated compositions. In low-rated compositions, "and" is incorrectly used, whereas high-rated compositions avoid its use but are assessed as textured.

Enhancements rank second with a frequency of 37 (31\%). Although these are moderately used, the students show a fair handling of these conjunctive elements. In most identified cases, they meaningfully relate to other parts of the clauses.

The least employed were items of elaboration, with only 4 instances (3\% of the items). This clearly depicts that the students have yet to master the mechanics of connectivity through conjunctions.

Finally, a list of the conjunctive items used by the students was generated: then, as a result, because, after, and, also, but, even, in a nutshell and even though. There were only eleven cohesive conjunctions found in the writings of the students. 


\section{B. Limitations of the Study}

This study has revealed the general pattern of conjunction use in high school students' English writing, but it fails to provide a reasonable explanation for this distribution.

Also, the sample size of this study is relatively small, the generalibility result is not satisfactory.

\section{REFERENCES}

[1] M. A. K. Halliday and R. Hasan, Cohesion in English, London: Longman, 1976

[2] W. Yang and Y. Sun, "The use of cohesive devices in argumentative writing by Chinese EFL learners at different proficiency levels," Linguistics and Education, vol. 23, no. 1, pp. 31-48, 2012

[3] S. A. Crossley and D. S. McNamara, "Computational assessment of lexical differences in L1 and L2 writing," Journal of Second Language Writing, vol. 18, no. 1, pp. 119-135, 2009.

[4] S. Y. S. Mohamed and A. K. Mudawi, "Investigating the use of cohesive devices in English as the second language writing skills," International Journal of Recent Scientific Research, vol. 6, no. 4, pp. 3484-3487, 2015.

[5] I. Jabeen, A. Mehmood, and M. Iqbal, "Ellipsis, reference and substitution as cohesive devices: The bear by Anton Chekhov," Academic Research International, vol. 4, no. 6, pp. 123-131, 2013.

[6] S. Kaur, "A study of cohesion devices in John Keats' Ode to Autumn," Modern Research Studies, vol. 2, no. 1, pp. 134-143, 2015.

[7] E. A. S. A. Ayyash, "The role of cohesive devices and the interplay of theme and rheme in consolidating the argument of Krauthammer's free lunch egalitarianism," Arab World English Journal, vol. 4, no. 4, pp. 235-251, 2013
[8] J. Bae, "Cohesion and coherence in children's written English: Immersion and English-only classes," Issues in Applied Linguistics, vol. 12, no. 1, pp. 51-88, 2001.

[9] C. Green, "A computational investigation of cohesion and lexical network density in L2 writing," English Language Teaching, vol. 5, no. 8, pp. 57-69.

[10] M. Bloor and T. Bloor, The Practice of Critical Discourse Analysis: An Introduction, London: Hodder Education, 2007.

[11] M. A. K. Halliday and C. Mathiessen, An Introduction to Functional Grammar, London: Edward Arnold, 2004.

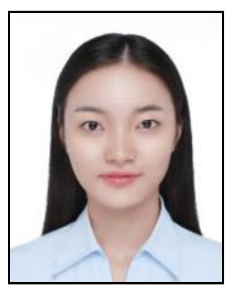

Li Yingle comes from Shaanxi Province, China. She was born in December, 1995. The author got her bachelor degree in China Agricultural University in 2017. Now she is a graduate student majoring in applied linguistic at Northwestern Polytechnical University, China.

She was an assistant teacher at Northwestern Polytechnical University for three semesters. Now she is a part-time counsellor at the same university.

Ms. Li had published one conference article at the 7th Annual International Conference on Language, Literature and Linguistics in 2018, Singapore named The Features of Rural Fiction in Tess of the d'Urbervilles. Ms. Li won twice the Second Prize Award of Academic Scholarship for master degree students, the Second Prize Award of The SWOT Research Challenge and Elite Challenge in 2018 at Northwestern Polytechnical University, China 